\title{
Notas biográficas y pedagógicas sobre el padre Feijoo
}

Valentín Martínez-Otero Pérez Universidad Complutense de Madrid

\section{Resumen}

El benedictino español Benito Feijoo (1676-1764) fue uno de los intelectuales más destacados del siglo XVIII. Sus aportaciones al mundo del pensamiento y la cultura abarcan un buen número de ensayos sobre los saberes eruditos y populares de la época. En lo que se refiere al gran alcance pedagógico de Feijoo, se advierte a un tiempo en su condición de profesor universitario, en su compromiso crítico y empírico con la eliminación de errores y en su actitud crítica y empirista, que le lleva a poner en entredicho obsoletos métodos de enseñanza. La obra del benedictino, aunque es ensayística y carece de sistematización, tiene una finalidad educativa. Este artículo, tras repasar algunos datos biográficos, se centra en algunas de sus contribuciones pedagógicas más destacadas, como el cultivo del entendimiento y la defensa de las mujeres. En definitiva, Feijoo es un iniciador, un educador de gran relevancia histórica que, en el marco de su elevada misión pedagógica, logró agitar las conciencias. Por ello, su excelsa figura continúa brillando y se sigue estudiando en este siglo XXI. Palabras clave: Benito Feijoo. Ilustración española. Biografía. Pedagogía.

\section{Biographical and pedagogical references about Feijoo father}

\section{Abstract}

The Spanish Benedictine Benito Feijoo (1676-1764) was one of the most prominent intellectualsof the 18th century. His contributions to the world of thought and culture extend a significant number of essays about scholars and popular knowledge of the time. In reference to the pedagogy success of Feijoo, it is worth mentioning his condition as a university professor, his critical and empirical agreement with the omission of mistakes and also his critical and empirical behavior which questions obsolete teaching methods. Although the work of the benedictine is an essay, it has an educational purpose. This article begins with his biographical data and the focuses on some of his most important pedagogical contributions, with the promotion of the understanding and protection of women. In conclusion, Feijoo is a founder, in other words, on of the most important educators who in the context of his pedagogy mission gets to incite the consciences. For this reason his figure is still shining as a mark of reference in the 21 st century.

Keywords: Benito Feijoo. Spanish illustration. Biography. Pedagogy. 


\section{Notas biográficas e pedagógicas sobre o padre Feijoo}

\section{Resumo}

O beneditino espanhol Benito Feijoo (1676-1764) foi um dos intelectuais mais destacados do século XVIII. Suas contribuições ao mundo do pensamento e da cultura compreendem um significativo número de ensaios sobre os saberes eruditos e populares da época. No que diz respeito ao grande alcance pedagógico da obra de Feijoo, queremos ressaltar, tanto em sua qualidade de professor universitário, e seu compromisso crítico e empírico para a eliminação de erros, como também o questionamento a métodos de ensino ultrapassados. A obra do beneditino, embora seja ensaística e carecendo de sistematização, tem um propósito educacional. Este artigo, inicia-se com seus dados biográficos, depois, centra-se em algumas de suas contribuições pedagógicas mais destacadas, como a promoção do entendimento e da defesa das mulheres. Em suma, Feijoo é um iniciador, um educador de grande relevânciahistórica que, no contexto da sua alta missão pedagógica, conseguiu agitar consciências. Portanto, sua figura sublime continua a brilhar e ainda está sendo estudado neste século XXI.

Palavras-chave: Benito Feijoo. Iustração espanhola. Biografia. Pedagogia.

\section{Introducción}

En el marco de esta introducción ofrecemos algunos datos biográficos de Benito Jerónimo Feijoo, que nació en Casdemiro (Orense), el 8 de octubre de 1676 y falleció en Oviedo, con casi 88 años, el 26 de septiembre de 1764. Se sabe' que a temprana edad, antes de los catorce años, ingresó en el monasterio de San Julián de Samos propiedad de la Orden de San Benito, donde recibió el hábito monástico en 1690. Estudió Artes en el Colegio de San Salvador de Lérez (Pontevedra), Teología en el de San Vicente en Salamanca y amplió sus conocimientos en San Pedro de Eslonza, en León. En 1709 se le nombró maestro de novicios para el Colegio de San Vicente de Oviedo, donde fue abad desde 1721 y consiguió la cátedra de Teología en la Universidad, desde la que ejerció su magisterio durante treinta años.

Datos recogidos ${ }^{2}$ sobre Feijoo revelan que, a diferencia de sus anteriores destinos, de los que apenas se sabe nada, su vida en Oviedo es bastante conocida. La actividad docente, a la que a partir de 1725 se agrega la redacción de sus obras mayores, se complementaba con los compromisos religiosos, el consejo a las personas que acudían a él y la conversación con amigos y 
conocidos, a los que atendía en su celda, en la calle o en las casas a que era invitado. Aunque consagrado al pensamiento, la oración y la lectura no fue un monje retraído que vivió aislado en su celda. Más bien fue un hombre comunicativo, accesible y afable, muy visitado, incluso por personas que se desplazaban ex profeso a Oviedo, que abría generoso su biblioteca y que mantuvo una intensa actividad epistolar. Era, además, un gran orador que, desde el púlpito, entusiasmaba a cuantos acudían a escuchar sus sermones. Complementariamente, realizó numerosos viajes, aunque en los límites establecidos por sus obligaciones y "[...] pudo conocer a fondo la realidad física y social de Galicia, montaña de León y, especialmente, Asturias, sobre la que hay múltiples referencias en su obra. Menos son las que hace de los lugares en que hizo su formación, y tampoco es mucho lo que dice de Madrid".

Por la misma fuente consultada ${ }^{3}$ sabemos que fue querido y respetado, y que llevó, en general, una vida apacible en Oviedo. Los sinsabores le llegaron sobre todo de fuera, particularmente por las críticas de sus opositores y por la humillante sanción inquisitorial que ordenaba borrar algunos pasajes suyos en los que atenuaba la presunta condición pecaminosa de los bailes y las visitas privadas.

14 Lector empedernido, con gran curiosidad intelectual, estuvo al corriente de las novedades culturales: "Toda su obra proclama la amplitud de sus lecturas y la consulta directa de las más afamadas revistas del momento"4. Como dijera Fr. José Pérez, tenía también grandes cualidades como escritor: "Nada escribe dos veces, sin interpolación corre y aun vuela su pluma, ni un ápice suele añadir a lo que una vez escribe, rarísima vez cancela aun una sola cláusula" ${ }^{\prime}$.

He aquí resumidos otros datos y rasgos de Feijoo':

- Alegre y jovial, espléndido y caritativo. Su munificencia se manifestó nítidamente durante la hambruna de 1741 y 1742, en la que, para auxilio de muchos campesinos, compró gran cantidad de grano y contrató a varias personas para que lo distribuyeran en Oviedo y en muchas aldeas.

- Profundo sentido religioso y austeridad en sus costumbres. Su conducta se distinguía por la naturalidad y la sencillez; su mentalidad secular le permitía diferenciar lo religioso de lo civil; cultivador del trabajo, la amistad, la solidaridad, la responsabilidad social...; gozador de placeres permitidos como el arte, la música, los paseos por el campo, la conversación, el chocolate, el 
tabaco.... Admirador de Tomás Moro, político inglés, gran humanista, autor de Utopía.

- Mostraba una nítida actitud pedagógica para "sacar al vulgo de sus errores". Dotado de extraordinarias cualidades humanas e intelectuales. Al ver la luz el primer tomo del Teatro crítico surgieron impugnadores y detractores, pero sintió igualmente el reconocimiento de su valía y la adhesión de sus lectores nacionales y extranieros.

- Artífice de un dilatado y original programa de reforma intelectual encaminado a sacudir la pereza del pensamiento y a estimular la reflexión. Fomenta el espíritu crítico y la lectura, desenmascara mitos y prejuicios, derriba dogmatismos y favorece un saludable escepticismo, rescata los nuevos conocimientos científicos y filosóficos del extranjero y difunde los nacionales, impulsa el racionalismo experimental, combate el monopolio escolástico, la charlatanería, el misoneísmo, la xenofobia y todo tipo de corporativismos, anima a evitar las ideas fosilizadas y a depurar la religiosidad de supersticiones y falsedades. Promueve, en suma, el progreso, la búsqueda de la verdad, la tolerancia y la apertura a Europa. Aborda críticamente en castellano, no en latín, una gran variedad de materias: medicina, ciencias naturales, historia, supersticiones y creencias populares, filosofía, políitica, literatura y teoría literaria, filología, música, derecho, demografía, urbanidad, estética, enseñanza pública, moral, etc.

- Se sirve en el diseño general de su obra de la "literatura mixta" o miscelánea y en el tratamiento específico de los temas, del "discurso" o ensayo. Más adelante, optará por la "carta". Su escritura es clara, precisa, natural, bella, viva y prudente. Como recoge Marichal (1951, p. 321), en muchos aspectos es un oráculo cuya obra tuvo gran resonancia: "Feijóo es quizá el primero de los ensayistas españoles que escribe cara al público, pensando en un vasto público". Entre sus lectores pronto se distinguen dos grupos crecientes y enfrentados. Por un lado, sus devotos, que le consideran guía y mediador cultural, y, por otro, sus detractores, dispuestos a atacarle con cualquier pretexto. Surge pronto un tercer grupo: personas que allende nuestras fronteras tienen interés por su obra, sea en español o en las lenguas a las que ya en vida del propio benedictino es traducido: francés, italiano, inglés, portugués y alemán.

- La proyección intelectual de Feijoo es uno de los fenómenos culturales más destacados del siglo XVIII y un caso excepcional en la historia editorial 
de libros de pensamiento, pues se suceden desde el principio las reimpresiones y las ediciones de sus obras.

- Autor muy polémico. Muchas de sus ideas se discutieron ampliamente. Entre las cuestiones controvertidas estaba su defensa de la mujer y su posición sobre la racionalidad de los brutos. Lo verdaderamente importante era la agitación ideológica que sobre estos asuntos y otros muchos se produjo. Despertó el interés por la ciencia y el pensamiento, se promovió la lectura y se difundieron nuevas ideas.

- Muy popular, con gran reconocimiento intelectual. A su muerte, no sólo los ovetenses concurrieron a rendirle tributo, sino también personas llegadas de muy diversos lugares. Postrera expresión pública del hondo lamento por el fallecimiento de un hombre sabio y benemérito de España, de la república literaria y de toda la humanidad, a cuyo desengaño y utilidad dedicó sus reflexiones, estudios y sus muchas obras ${ }^{7}$.

\section{Quijotesco perfil pedagógico del padre Feijoo}

Feijoo brilla intensamente con luz propia en la Historia de la Educación.

16 Un intelectual enciclopédico que, como dice De Fraga (1950), fue un educador en todos los sentidos posibles. Por una parte, se consagró durante décadas a la enseñanza en la Universidad de Oviedo, de la que fue catedrático. Por otra, con ágil y esforzada pluma se dedicó sin descanso a desengañar al vulgo. Con sus escritos sobre numerosas materias, agitó las conciencias, derribó supersticiones y promovió la racionalidad. Su legado llega hasta nosotros.

De esta vertiente magisterial recibimos noticia del egregio Marañón (1954), uno de los principales estudiosos y recuperadores de la obra feijoniana. Nuestro excelso pensador dice que eligió a Feijoo "en el reino sin fronteras de la sabiduría pretérita", al que empezó a conocer siendo niño, en la biblioteca de su padre. Desde aquella edad, las obras del benedictino fueron para él una permanente lección: "Porque Feijoo fue, ante todo, un gran maestro, de los que lo son para todos y para siempre." Más adelante, leemos: "El secreto del triunfo clamoroso de Feijoo está en otra cosa; no en la obra misma, sino en la "persona del autor» o mejor dicho, en lo que en su obra había de gesto público, de actitud social" (MARAÑón, 1954, p. 10). Y continúa: 
Feijoo sólo quería el bien de su Patria y el de los hombres en general; y ningún bien, decía, es superior al de la verdad. Para él, naturalmente, este deseo no podía negar ni a la Teología ni al orden social, aunque sí pudiera parecérselo a muchos de los que, en todas las épocas, se atribuyen gratuitamente la representación de la ortodoxia y del orden social sobre la tierra. Para hacer ver la verdad a los españoles, sumidos en la ignorancia (o en la pedantería, que es la forma universitaria de la ignorancia), Feijoo tenía que aparecer rebelde frente a los convencionalismos en los que se apoya (y ello es inevitable), una parte del andamiaje social. No hay en este trance términos medios: o recluirse, sin rechistar, en la celda del convento, en la celda que todos tenemos en casa, - arriesgar la celda de la cárcel, por el delito de no creer en los convencionalismos, aun cuando se reconozca que puedan ser, de momento, necesarios (MARAÑóN, 1954, p. 12).

En Feijoo encontramos un maestro, un pedagogo social de espíritu quijotesco. De nuevo, la palabra sabia de Marañón:

Feijoo, en nombre de la verdad, acometió los errores de los hombres de ciencia, de los universitarios, de los críticos, de los historiadores, de los médicos, es decir, de las gentes autorizadas que le rodeaban; y, más aún, su examen implacable del error, llegó hasta algunas gentes de la lglesia que merecían, y él demostró que lo merecían, el vapuleo (MARAÑÓN, 1954, p. 10).

Y si Marañón nos recuerda la magna lección feijoniana, ¿̇nos atreveremos a despreciarla? Una lección de pensamiento serio, sólido y comprometido, de amor a la verdad y a la humanidad.

De Fraga (1950) enfatiza el asturianismo del padre Feijoo. Aunque gallego, una vez en Oviedo, prácticamente no sale de la ciudad, salvo un viaje corto a Madrid para asuntos de la edición de sus obras. Hace continuas alusiones a Oviedo en sus escritos y rechaza altos cargos para no desviarse de su labor realizada desde el convento de San Vicente ${ }^{8}$. A la sazón, y gracias a Feijoo, Oviedo es uno de los centros irradiadores de la cultura.

Por su vocación y profesión de desengañador del vulgo, de deshacedor de errores, bien dice De Fraga (1950), que Feijoo merece el dictado de pedagogo. Y agrega que la mayor innovación pedagógica de Feijoo es la apología y difusión del método experimental. A este respecto, Palacios (2014) afirma que el espíritu científico que aparece en la obra feijoniana enlaza con 
Notas biográficas y pedagógicas sobre el Padre Feijoo

el empirismo de Bacon y se aparta del racionalismo de Descartes. En efecto, el benedictino escribe en El gran Magisterio de la experiencia:

Lo primero que a la consideración se ofrece es el poco o ningún progreso que en el examen de las cosas naturales hizo la razón, desasistida en la experiencia por el largo espacio de tantos siglos. Tan ignorada es hoy la naturaleza en las Aulas de las Escuelas, como lo fue en la Academia de Platón, y en el Liceo de Aristóteles. ¿Que secreto se ha averiguado? ¿Qué porción, ni aun pequeñísima, de sus dilatados países se ha descubierto? ¿Qué utilidad produjeron en el mundo las prolijas especulaciones de tantos excelentes ingenios como cultivaron la Filosofía por la vía del raciocinio? (FEIJOO, 1733, p. 259).

En la misma senda de reconocimiento pedagógico, De Fraga (1950) señala que el mayor escollo con que se topó Feijoo no era introducir un nuevo método, sino enfrentarse a los que a la sazón imperaban en la enseñanza universitaria: el método especulativo y el principio de autoridad. Uno y otro con facilidad conducían al extravío. Es muy ilustrativa la alegoría en que el padre Feijoo (1733) contrapone la experiencia (Solidína), sabia y sencilla, a la ima18 ginación (ldeária), ignorante y charlatana. La experiencia prueba sólidamente sus máximas con demostraciones sensibles, mientras que la imaginación funda las opiniones en la vana representación de sus ideas. Desgraciadamente, se lamenta el benedictino, durante mucho tiempo el examen de la realidad se hizo a partir de la imaginación (Ideária), con rechazo de la experiencia (Solidína).

En cuanto al principio de autoridad, Feijoo se queja de los perjuicios que ha generado. En el corolario del discurso Argumentos de autoridad puede leerse:

Es imponderable el daño que padeció la Filosofía, por estar tantos siglos oprimida debajo del yugo de la autoridad. Era esta, en el modo que se usaba de ella, una tirana cruel, que a la razón humana tenía vendados los ojos, y atadas las manos, porque le prohibía el uso del discurso, y de la experiencia. Cerca de dos mil años estuvieron los que se llamaban Filósofos estrujándose los sesos; no sobre el examen de la Naturaleza, sino sobre la averiguación de la mente de Aristóteles. Y como si fuese poco indecorosa para los Filósofos Cristianos, la denominación de un Gentil, le añadieron por Ministros, o por Consortes del Imperio dos Mahometanos. Ya se alteró mucho el gobierno de la República Literaria, por lo menos en 
las demás Naciones. Desposeyósele a Aristóteles del Trono, pero señalándole un honrado asiento. A Avicena, y a Averroes no les han dejado ni un rincón en el Aula. Creo, que esto es poner las cosas en razón; espero, que los Filósofos Españoles se conformen a una disposición tan justa (FElJOO, 1739, p. 53).

Podemos, en definitiva, decir que el alcance pedagógico de Feijoo se advierte entreveradamente en su condición de profesor universitario, en su compromiso crítico y empírico con la eliminación de errores y en su actitud crítica y empirista, que le lleva a cuestionar obsoletos métodos de enseñanza.

Delgado (1993) al referirse al magisterio feijoniano recuerda que toda la obra del benedictino, aunque asistemática y ensayística, tiene una finalidad educativa y está salpicada de elementos pedagógicos. Desde esta perspectiva elevadora, su ingente labor parte de una valoración crítica de la enseñanza del momento, tanto en lo que se refiere a la orientación última, a los métodos y a la didáctica como a los contenidos impartidos. Se trata de un planteamiento pedagógico moderno, utilitarista y pragmático, crítico con la enseñanza tradicional, encaminado a mejorar el nivel cultural y científico de la nación, como requisito de ulterior progreso. Campomanes y Jovellanos, entre otros, recogen sus propuestas e intentan seguir, con distinta suerte, el rumbo marcado por el "Padre Maestro".

De su actitud crítica hacia la enseñanza universitaria es muy ilustrativa su carta Causas del atraso que se padece en España en orden a las Ciencias Naturales, de la que recojo, en síntesis, los principales motivos aducidos por Feijoo:

- La primera es el corto alcance de algunos de nuestros Profesores. Hay una especie de ignorantes perdurables, precisados a saber siempre poco, no por otra razón, sino porque piensan que no hay más que saber que aquello poco que saben.

- La segunda causa es la preocupación, que reina en España contra toda novedad. Dicen muchos, que basta en las doctrinas el título de nuevas para reprobarlas, porque las novedades en punto de doctrina son sospechosas, esto es confundir a Poncio de Aguirre con Poncio Pilatos.

- La tercera causa es el errado concepto de que cuanto nos presentan los nuevos Filósofos, se reduce a unas curiosidades inútiles. 
- La cuarta causa es la diminuta, o falsa noción, que tienen acá muchos de la Filosofía Moderna, junta con la bien, o mal fundada preocupación contra Descartes.

- La quinta causa es un celo, pío sí, pero indiscreto, y mal fundado: un vano temor de que las doctrinas nuevas, en materia de Filosofía, traigan algún perjuicio a la Religión.

- La sexta, y última causa es la emulación lacaso se le podría dar peor nombre), ya personal, ya Nacional, ya faccionaria. Si Vmd. examinase los corazones de algunos, y no pocos de los que declaman contra la nueva Filosofía, o generalmente, por decirlo mejor, contra toda literatura, distinta de aquella común, que ellos estudiaron en el Aula, hallaría en ellos unos efectos bien distintos de aquellos, que suenan en sus labios. Oyeseles reprobarla, o ya como inútil, o ya como peligrosa. No es esto lo que pasa allá dentro. No la desprecian, o aborrecen; la envidian (FEIJOO, 1745, p. 215-225).

Como se han encargado de mostrar Llavona y Bandrés (1995), el padre Feijoo abordó con profusión las cuestiones psicológicas, algunas de alcance pedagógico. Es el caso de sus escritos sobre el entendimiento y las mujeres. Sobre ellos haremos algunos comentarios.

\section{El cultivo del entendimiento}

En la carta9 El estudio no da entendimiento, de ilustrativo título, escribe: "El estudio, los libros, los Maestros, no hacen ingenioso al que no lo era." Y continúa con esta bella, aunque en nuestra opinión desacertada metáfora:

[...] las noticias, que se adquieren con el estudio, hacen en el entendimiento lo que los tapices, o pinturas, que visten las paredes de un Palacio, que decoran el aspecto, sin mejorar el edificio; o lo que los anillos, con que se engalana una Damisela, que dan lucimiento a la mano, sin blanquear más la tez, o articular mejor su organización.' Prosigue la argumentación de Feijoo: 'Más diré a Vmd.: conocí, y traté por espacio de tres años a un Profesor de Teología Escolástica, y Moral, muy aplicado al estudio; pero con tan ninguna utilidad suya, que aún le dañaba su mucha aplicación; porque cuanto más estudiaba, menos sabía. Es hecho ciertísimo, aunque a Vmd. parezca increíble; y aunque solo observé en un sujeto, no dudo suceda lo mismo a otros, en quienes se junte el mucho estudio con 
una limitada comprensión, sin que sea muy oculto el principio de donde esto pende. Vmd. habrá notado, o por lo menos oído, que digieren, o actuan mal al alimento aquellos sujetos, que comen más cantidad, que la que es proporcionada a la actividad de su estómago. Lo mismo, pues, que a los estómagos débiles con el exceso de los manjares, sucede a las débiles, o cortas capacidades con la multitud de especies intelectuales, que son el alimento de las almas. Pueden digerir algunas pocas: pero siendo muchas, de su imperfecta cocción resulta una masa confusa, rudis, indigestaque moles, en que no aparece la idea bien distinta de objeto alguno (FEIJOO, 1760, p. $181-1821$.

Feijoo, al final de dicha carta, afirma que la auténtica sabiduría exige un entendimiento sobresaliente y un ingenio penetrante, sin que pueda alcanzarse mediante el estudio, la aplicación, los libros o los Maestros, pero agrega que la apariencia de sabio puede conseguirse con una receta que incluye los siguientes ingredientes:

Lo primero, una feliz memoria, en que se puedan almacenar muchas noticias literarias. Lo segundo, una constante aplicación a recoger multitud de éstas. Lo tercero, una abundante verbosidad. Y finalmente, una buena dosis de audacia, o satisfacción de sí mismo: de modo, que, suceda lo que sucediere, no se corte, ni acobarde jamás, que sea en actos públicos, ni en conversaciones privadas (FEIJOO, 1760, p. 185).

En torno a esta importante materia, hay autores, como De Fraga (1950), que aunque no se atreven a dar toda la razón al benedictino, están más cerca de su opinión que de la contraria. Por mi parte, debo decir que el eminente sabio, hijo de su tiempo, yerra. Que nos hallemos ante un pensador de primera fila no impide que, en ocasiones, pueda adoptar una posición endeble. Han trascurrido doscientos cincuenta años desde su muerte y obviamente en algunas cuestiones psicológicas y pedagógicas se ha avanzado de forma considerable. En relación a su planteamiento sobre el estudio y el entendimiento, podemos excusarle también, al menos parcialmente, si pensamos que a la sazón el aprendizaje universitario predominante tenía carácter memorístico. Este uso inadecuado o abusivo de la memoria no permite relacionar sustantivamente los nuevos contenidos de aprendizaje con lo ya conocido por el estudiante. Se trata de un aprendizaje mecánico, carente de significatividad, 
que no posibilita un genuino progreso intelectual. En el otro extremo, encontraríamos el aprendizaje significativo, promotor de comprensión, que presupone una concepción activa del alumno y se ve estimulado por una metodología docente flexible, dinámica y dinamizadora, problematizadora, impulsora de autonomía y colaboración.

El propio Feijoo se queja, entre otros vicios, del abuso de la memoria en la enseñanza:

Fuera del gran daño, que en la lectura de las Aulas ocasiona la prolijidad de los Maestros, resta otro, no sé si mayor, por el uso que obligan a hacer de ella a los Discípulos, precisándolos a mandarla a la memoria, y dar cuenta de ella palabra por palabra, y letra por letra, como va escrito. ¡Qué dispendio de tiempo tan lamentable! Un oyente, que podría largamente en dos horas de estudio hacerse cargo de un pliego de lectura, tomándola en substancia, se halla reducido aprender acaso sólo una plana. ¿Qué diríamos de quien teniendo un Caballo capaz de andar a legua por hora, poniéndole algún embarazo, que le retardase notablemente el movimiento, le precisase a caminar no más que a legua por día? Ello por ello; lo mismo viene a ser lo que pasa en nuestro caso (FElJOO, 1739, p. 39-40).

El espíritu ilustrado fue penetrando poco a poco en las adormecidas Universidades del siglo XVIII. El racionalismo y el método experimental con dificultad se abrían paso en unas instituciones ancladas en el pasado, con raíces medievales y presididas por el método aristotélico-tomista en la enseñanza.

La labor del padre Feijoo es trascendental en el proceso que conducirá a las reformas universitarias durante el reinado de Carlos III. Es uno de los inspiradores de las innovaciones que habrían de llegar. Más allá de eventuales equivocaciones, permanece, como diría Marañón (1954, p. 14), "[...] su actitud ante el error y la verdad [...]" en un tiempo en que la superstición se extendía por doquier, incluso en las oscuras Universidades, a menudo refractarias a las luces del pensamiento.

Tras la reflexión comprensiva en torno a la postura que Feijoo adopta al hablar del entendimiento, procede decir que ya es clásico el debate psicológico sobre si la inteligencia es estable o modificable. Esta discusión se inserta en otra más amplia, relativa a si la inteligencia depende de la herencia o del ambiente ${ }^{10}$. En su formulación básica, los defensores de la herencia 
- "nativistas" - consideran que la inteligencia es heredable y, por tanto, estable a lo largo de la vida. En el otro extremo, se sitúan quienes defienden la importancia del medio y de la educación - "ambientalistas" - . Por fortuna, como bien dice Pinillos (1999), no hay psicólogos serios que mantengan una posición unilateral sobre esta cuestión, hasta el punto de que la conjunción adversativa o ha sido sustituida por una y que, aunque de modo impreciso, indicaría la aceptación de la correlatividad esencial de la herencia y del ambiente a la hora de explicar la inteligencia de los sujetos.

Así pues, y aunque esté por esclarecer -lo que acaso sea imposible, al menos en sus términos definitivos - qué cuantía corresponde a la herencia y al medio en la dotación intelectual personal, hemos de reconocer que los procesos genéticos y ambientales interactúan y explican conjuntamente la inteligencia humana. Como es innegable, en esta concurrencia, particularmente en lo que se refiere al entorno, no puede soslayarse el influjo de la educación - y con ella del estudio -, labor humanizadora por antonomasia. Desde luego, no se trata de hacer milagros. Según el conocido proverbio: "Quod natura non dat, Salmantica non præestat" (Lo que la naturaleza no da, Salamanca no (lo) presta), pero desde un optimismo pedagógico moderado, en la actualidad en boga, así como es descartable pensar que la educación es omnipotente también debe rechazase la total desconfianza en su virtualidad. El conocido trabajo de Rosenthal y Jacobson ${ }^{11}$ (1980) demostró que las expectativas de los profesores sobre el rendimiento intelectual de sus alumnos pueden llegar a realizarse. Admitido este proceso de autocumplimiento, se ha de animar a los educadores para que alberguen expectativas realistas y positivas sobre su propia labor, al igual que equilibrada confianza en las posibilidades de los educandos.

En conclusión, insistamos en que un gran potencial intelectual al nacer, no garantiza su efectivo despliegue, que depende, en última instancia, de la educación. Por mucha capacidad intelectual innata que se posea, si no se dispone de las condiciones educativas apropiadas se echa a perder. Más agradece el sediento la copa pequeña y colmada que la grande y vacía. La educación es la fuente de la que brota el agua vivificadora. 


\section{La defensa de las mujeres}

El discurso Defensa de las mujeres (FElJOO, 1726) se inicia con el comentario de que el vilipendio de las mujeres es generalizado y se extiende a la vertiente moral, física y sobre todo a su "limitado" entendimiento. Procede a mostrar, en cada plano indicado, lo que a su juicio son débiles argumentaciones con que se sostiene que las mujeres, por lo común, son peores que los hombres. Critica así el desprecio que, de un modo u otro, reciben las mujeres en el Corán y en otros importantes libros. Se centra después en la dimensión física y reprocha que la mujer sea considerada por algunos "animal imperfecto, y aun monstruoso". Reprueba, por ejemplo, la iniquidad de Aristóteles, que proclamó los supuestos defectos físicos y morales de las mujeres. También ataca otro error teológico:

[...] impugnado por S. Agustín, lib. 22 de Civit. Dei, c. 17, cuyos Autores decían que en la Resurrección Universal esta obra imperfecta se ha de perfeccionar, pasando todas las mujeres al sexo varonil; como que la gracia ha de concluir entonces la obra que dejó sólo empezada la naturaleza (FEIJOO, 1726, p. 330).

Feijoo tampoco se muestra conforme con quienes inclinan la balanza del lado de las mujeres. Su afán es la igualdad, y así afirma que, aunque se pueda atribuir ventaja a los varones en lo que a robustez, constancia y prudencia se refiere, las mujeres empatan merced a tres cualidades más presentes en ellas: hermosura, docilidad y sencillez. A estas tres notas femeninas agrega el benedictino una cuarta, la vergüenza, que preserva de ciertas acciones. Pone después ejemplos de mujeres con dotes políticas y económicas, con valeroso heroísmo y ardor guerrero, con merecida confianza aun en circunstancias extremas. Y llega a la cuestión que considera capital, la relativa al entendimiento de las mujeres, generalmente despreciado por "hombres superficiales".

El padre Feijoo explica que la falta de instrucción ${ }^{12}$ de muchas mujeres no debe interpretarse como incapacidad. Por mucho entendimiento que tengan, si carecen de información quedarán deslucidas al tratar diversos temas. No encuentra, pues, fundamento a la pretendida "desigualdad entre los sexos", ni siquiera en razones asentadas en el diferente tamaño cerebral:

Si la diferente magnitud de la cabeza, o del celebro indujera desigualdad en las operaciones del entendimiento, se hallaría ser muy 
desiguales en entender, y percibir los hombres muy desiguales en la estatura, pues a proporción de ella son mayores, o menores, así el cráneo, como el celebro; lo cual es contra la observación (FEIJOO, 1726 , p. 357).

Posteriormente, Feijoo se adentra en las "amenidades de la Historia" y ofrece numerosos ejemplos de mujeres ilustres, que florecieron en los últimos siglos, en España y en otros países europeos. Incluso cita un caso reciente en Asia: "para prueba de que no está la gloria literaria de las mujeres encarcelada en la Europa."

$Y$, en definitiva, afirma:

Mi voto, pues, es, que no hay desigualdad en las capacidades de uno y otro sexo. Pero si las mujeres para rebatir a importunos despreciadores de su aptitud para las Ciencias, y Artes quisieren pasar de la defensiva a la ofensiva, pretendiendo por juego de disputa superioridad respecto de los hombres, pueden usar de los argumentos propuestos arriba, donde de las mismas máximas físicas, conque se pretende rebajar la capacidad de las mujeres, mostramos que con más verisimilitud se infiere ser la suya superior a la nuestra (FEIJOO, 1726, p. 384).

Ahora, una vez recogido en síntesis el discurso de Feijoo sobre la igualdad intelectual intergéneros, nos vamos a referir desde el prisma científico, primordialmente psicológico y de alcance social y pedagógico, a las diferencias en la inteligencia de hombres y mujeres. Nos hallamos ante una cuestión controvertida cuyo interés, hoy como ayer, desborda el ámbito científico y penetra de lleno en el terreno político e ideológico. En el siglo XVIII, al igual que muchos siglos antes, la mujer era, en general, peor considerada que el hombre. En muchos casos puede hablarse de auténtica misoginia, esto es, aversión u odio a las mujeres, generalmente por parte de los hombres. Alonso Fernández (2005), por ejemplo, localiza la misoginia en el terreno de las ideas, en las religiones, en la historia e incluso en la modernidad, en la que experimenta significativas fluctuaciones: aparición social de la mujer (siglo XVIII), antifeminismo a ultranza (siglo XIX ${ }^{13}$ ), liberación de la mujer (siglo XX). Podríamos agregar que en este siglo XXI se está avanzando en la liberación femenina.

Históricamente, la mujer, al ser comparada en el plano intelectual con el hombre, ha salido muy mal parada, considerada incluso como frágil 
mental (imbecillitas mulierum). Ragel (1994-1995), por ejemplo, recuerda que durante el Renacimiento algunos países europeos lanzaron la vista a los tiempos paganos y generalizaron esa idea de debilidad intelectual femenina, lo que se traducía, obviamente, en una discriminación en los derechos de la mujer respecto a los del varón. Y agrega el mismo autor que en los siglos XVII, XVIII y XIX se produjeron pocos cambios, hasta el punto de que no era extraño que se equiparase psicológicamente a las mujeres con los niños o con los deficientes mentales, lo que permitía justificar su inferioridad jurídica.

En el terreno de la Psicología Diferencial, ya hace años (1984), la profesora Tyler (1984), que por cierto llegó a ser presidenta de la American Psychological Association (APA), señalaba, a partir de diversas investigaciones, que más buscar diferencias absolutas en inteligencia medida a través de tests acaso interesaría evaluar aptitudes específicas. A este respecto, indica que en aptitud verbal, y en concreto en fluidez, las mujeres se expresan desde la infancia y hasta la madurez con más rapidez y exactitud que los hombres. En relación a la aptitud matemática, suelen obtener puntuaciones más altas los varones, sobre todo en los tests que requieren razonamiento matemático más que en los que exigen cálculos sencillos. En cuanto a juicio y manipulación de 26 relaciones espaciales, los hombres, en general, obtienen mejores resultados, pero en tareas que requieren destreza manual la ventaja corresponde a las mujeres. Lo mismo sucede en pruebas de memoria repetitiva y en percepción rápida de detalles, en las que a menudo son las mujeres las que sobresalen. En ciencias el rendimiento es mayor en los varones.

Tyler (1984) recuerda que en la discusión sobre las diferencias de promedio, como las señaladas, hay que tener en cuenta la variabilidad, al igual que las medidas centrales. De acuerdo con la teoría de la mayor variabilidad masculina, los hombres tienden más a situarse en los extremos, mientras que las mujeres se concentran más en el término medio. De cualquier modo, la mayor parte de los trabajos que tratan de probar esta teoría de la mayor variabilidad masculina arrojan resultados controvertidos y poco concluyentes.

Desde Alemania, los profesores Amelang y Bartussek (1991, p. 176) señalan también, a partir de diversas investigaciones, que en inteligencia general no hay diferencias significativas en los valores medios obtenidos por hombres y mujeres en los tests. Agregan los autores consultados, tras la revisión de varios estudios, que en áreas funcionales específicas parece haber diferencias sistemáticas entre los sexos: las mujeres suelen ser superiores en fluidez 
verbal, gramática, vocabulario y lectura, es decir, en el área verbal, mientras que los varones obtienen mejores resultados en representación espacial y, en consecuencia, en comprensión técnica.

En trabajos más recientes, como los firmados por la neuropsiquiatra Brizendine (2012) sobre el "cerebro femenino" y el "cerebro masculino", se insiste en que este órgano, según se trate de mujeres o de hombres, está tan influido por las respectivas hormonas, que puede hablarse de una realidad femenina o masculina. Además, esta autora afirma que si bien los varones y las mujeres tienen el mismo nivel promedio de inteligencia, la realidad del cerebro femenino con frecuencia ha sido mal interpretada por entender que está menos capacitado en ciertas áreas como las matemáticas y la ciencia.

Comoquiera que sea, al explicar los desemejantes resultados que eventualmente obtengan varones y mujeres en pruebas de aptitudes intelectuales concretas hay que recurrir también al proceso educativo - familiar y escolar -, que puede, por ejemplo, contribuir significativamente a la configuración de actitudes e intereses diferenciales según el género $y$, por ende, al desigual despliegue de capacidades, incluso en edades tempranas. En este mismo sentido, hacemos hincapié en que la educación ha de promover la igualdad de oportunidades, de manera que la persona, con independencia del género, se pueda desarrollar plenamente. La educación de la inteligencia unidiversa, concepto al que ya me he referido, asume ese compromiso humanizador y, vuelta ahora la mirada hacia la Historia, reconocemos la labor apologética femenina realizada por Feijoo, así como su valiosa contribución a la consideración y a la educación de las mujeres.

\section{A modo de conclusión}

Recibimos con agradecimiento y admiración el legado de Feijoo, doscientos cincuenta años después de su muerte. Aunque el espíritu crítico, pragmático y pedagógico del maestro benedictino contribuyó al avance sociocultural de España, falta, como dice Delgado (1993), precisar la naturaleza y la relevancia de Feijoo en la Historia del Pensamiento y de la Pedagogía.

El papel de la educación es central en la obra de Feijoo, quien, en muchos aspectos, es un adelantado, un modernizador. Llevado por su actitud desengañadora es autor de un vasto programa de reforma intelectual, en el 
que, por ejemplo, cuestiona el escolasticismo y propugna el racionalismo experimental. Este egregio polígrafo, comprometido con el progreso, impulsa la búsqueda de la verdad en innúmeros campos del saber. Por supuesto, esto no quiere decir que esté libre de errores. La ciencia avanza y en su obra advertimos en la actualidad algunas equivocaciones, que, sin embargo, no amenguan el valor de su magisterio. Es el caso de algunas ideas sobre el cultivo del entendimiento, según ha quedado recogido en este texto. Al margen de ciertos yerros totalmente comprensibles, permanece el acierto de su magna labor. Por eso, con este modesto trabajo queremos rendir humilde tributo al excelso pedagogo y a su relevante e impactante obra, que tanto contribuiría al adelanto social, cultural y científico de España. Como pequeña muestra, los dos discursos aquí comentados relativos respectivamente al despliegue de la inteligencia y a la defensa de las mujeres. A despecho de su singularidad, ambos escritos reflejan su pensamiento valioso, valiente, controvertido, brillante, elegante, inteligente, apasionado, original y quijotesco.

En definitiva, hallamos en Feijoo, un precursor, un educador de gran significación histórica que, desde Oviedo, abierto al mundo y en el marco de su elevada misión pedagógica, logró agitar las conciencias. Por ello, su 28 excelsa figura ha de seguir inspirando y orientando nuestro rumbo en este siglo $X X I$.

\section{Notas}

1 Enciclopedia de Oviedo. Benito Jerónimo Feijoo Montenegro. Disponible en: http:// el.tesorodeoviedo.es/index.php?title=Benito_Jer\%C3\%B3nimo_Feijoo_Montenegro. Fecha de consulta: 22 mar. 2014.

2 Biblioteca virtual Miguel de Cervantes. Benito Jerónimo Feijoo. El autor: biografía. Feijoo y los orígenes de la llustración. Disponible en: http://www.cervantesvirtual.com/portales/benito_jeronimo_feijoo/autor_biografia/Fecha de consulta: 22 mar. 2014.

3 Biblioteca virtual Miguel de Cervantes.

4 Biblioteca virtual Miguel de Cervantes.

5 Biblioteca virtual Miguel de Cervantes.

6 Biblioteca virtual Miguel de Cervantes.

7 Véase la obra: Breve expression del grave sentimiento, con que el Real Colegio de San Vicente de Oviedo de el orden de San Benito, lamentó la muerte de el Illmo. y Rmo. Señor Don Fr. Benito Geronymo Feijoo, y Montenegro, de el consejo de su Majestad, \&c. en los dias 16. y 17. de Diciembre año de 1764, Salamanca, por Antonio Villargordo y Alcaráz. 
8 Lo que fuera el convento de San Vicente está ocupado en la actualidad por la Facultad de Psicología de la Universidad de Oviedo.

9 FElJOO, B. (1760): "El estudio no da entendimiento", Cartas eruditas y curiosas. Tomo V. Carta VI, (Proyecto Filosofía en español). Documento disponible en: http://www.filosofia.org/bjf/ bjfc506.htm Texto tomado, según indica el Proyecto Filosofía en español, de la edición de Madrid 1777 (en la Imprenta Real de la Gazeta, a costa de la Real Compañía de Impresores y Libreros). Fecha de consulta: 18 de abril de 2014.

10 Recuérdese a este respecto la célebre polémica recogida en el libro: EYSENCK, H. J. y KAMIN, L. (1991): La confrontación sobre la inteligencia. ¿̇Herencia-ambiente? Madrid, Pirámide.

11 El llamado "efecto Pygmalion", una profecía autorrealizada, permitió comprobar que las expectativas de los profesores sobre el rendimiento intelectual de alumnos supuestamente con mayor potencial, aunque en realidad escogidos al azar, tendían a cumplirse. Véase: ROSENTHAL, R. y JACOBSON, L. (1980): Pygmalion en la escuela, Madrid, Marova.

12 Feijoo admite que la instrucción y la comunicación con sabios favorece la inteligencia, lo cual, en cierto modo, parece contradecir su tesis, ya comentada, de que el estudio no da entendimiento.

13 En relación a la infravaloración intelectual decimonónica de las mujeres puede consultarse, por ejemplo, el trabajo firmado por BOSCH, E. y FERRER, V. (2003): "Sobre la supuesta inferioridad intelectual de las mujeres. El caso de las teorías frenológicas en el siglo XIX", Clepsydra (2), p. $119-133$.

\section{Referencias}

ALONSO FERNÁNDEZ, Francisco. La misoginia, una revisión histórica. Psicopatología, Valencia, v. 5, n. 2, p. 57-91, 2005.

AMELANG, Manfred y BARTUSSEK, Dieter. Psicología diferencial e investigación de la personalidad. Traducción Diorki. S. L. Barcelona: Herder, 1991.

$\mathrm{BOSCH}$, Esperanza y FERRER, Victoria. Sobre la supuesta inferioridad intelectual de las mujeres. El caso de las teorías frenológicas en el siglo XIX. Clepsydra, La Laguna, v. 2, p. $119-133,2003$.

BRIZENDINE, Louann. El cerebro femenino. Traducción María José Buxó. Barcelona: RBA, 2012.

El cerebro masculino. Traducción Marta Pino Moreno. Barcelona: RBA, 2012a.

DE FRAGA TORREJÓN, Eduardo. Algunas notas pedagógicas sobre el padre Feijoo". Boletín del Instituto de Estudios Asturianos, Oviedo, v. 9, p. 89-1 10, 1950.

DELGADO CRIADO, Buenaventura. La reflexión pedagógica. Benito Jerónimo Feijoo. En: DELGADO CRIADO, Buenaventura (Coord.). Historia de la educación en España y América. 
Notas biográficas y pedagógicas sobre el Padre Feijoo

La educación en la España moderna (siglos XVI-XVIII). Madrid: Ediciones Morata-Ediciones SM, 1993.

EYSENCK, Hans Jürgen y KAMIN, Leon. La confrontación sobre la inteligencia ¿̇Herenciaambiente? Madrid, Pirámide, 1991.

FEIJOO, Benito. Argumentos de autoridad. Teatro crítico universal. Discurso 4, parágrafo 30. 1739 (Tomo VIII. Proyecto Filosofía en español. Texto tomado, según indica el Proyecto Filosofía en español, de la edición de Madrid 1779 (por D. Pedro Marí, a costa de la Real Compañía de Impresores y Libreros). Disponible en: http://www.filosofia.org/bjf/bjft804. htm. Acceso em: 17 abr. 2014.

Causas del atraso que se padece en España en orden a las Ciencias Naturales. Cartas eruditas y curiosas. 1745. (Tomo II. Carta XVI, (Proyecto Filosofía en español. Texto tomado, según indica el Proyecto Filosofía en español, de la edición de Madrid 1773 (en la Imprenta Real de la Gazeta, a costa de la Real Compañía de Impresores y Libreros). Disponible en: http://filosofia.org/bjf/bjfc2 16.htm. Acceso em: 18 abr. 2014.

Defensa de las mujeres. Teatro crítico universal. Discurso 16, 1726. (Tomo I. Proyecto Filosofía en español. Texto tomado, según indica el Proyecto Filosofía en español, de la edición de Madrid 1778 (por D. Joaquín Ibarra, a costa de la Real Compañía de 30 Impresores y Libreros). Disponible en: http://www.filosofia.org/bjf/bjtt 16.htm. Acceso em: 12 mayo 2014.

El estudio no da entendimiento. Cartas eruditas y curiosas. Carta VI, 1760. (Tomo V. Proyecto Filosofía en español). Disponible en: http: / / www.filosofia.org/bjf/bjfc506.htm. Acceso em: 20 mayo 2014.

El gran Magisterio de la experiencia. Teatro crítico universal. Discurso 11, parágrafo 10. 1733 (Tomo V. Proyecto Filosofía en español). (Texto que se toma, según señala el Proyecto de Filosofía en español, de la edición de Madrid 1778 (por D. Blas Morán, a costa de la Real Compañía de Impresores y Libreros). Disponible en: http://www.filosofia. org/bjf/bjft5 11 .htm. Acceso em: 16 abr. 2014.

El gran Magisterio de la experiencia. Teatro crítico universal. Discurso 1 1, parágrafo 10. 1733. (Tomo V. Proyecto Filosofía en español). (Texto que se toma, según señala el Proyecto de Filosofía en español, de la edición de Madrid 1778 (por D. Blas Morán, a costa de la Real Compañía de Impresores y Libreros). Disponible en: http:/ / www.filosofia. org/bjf/bjft511.htm. Acceso em: 16 abr. 2014.

LLAVONA, Rafael y BANDRÉS, Javier. La psicología en la obra de Benito G. Feijoo. Psicothema, Oviedo, v. 7, n. 1, p. 189-217, 1995. 
MARAÑ́N, Gregorio. Consideraciones sobre Feijoo. La Nueva España, Oviedo, p. 8-12, marzo, 1954. (Órgano provincial de la Falange Española Tradicionalista y de las JONS), Disponible en: http://www.filosofia.org/hem/dep/Ine/1954c31.htm. Acceso em: 4 jun. 2014.

MARICHAL, Juan. Feijoo y su papel de desengañador de las Españas. Nueva Revista de Filología hispánica, Ciudad de México, n. 5, p. 313-323, 1951.

MARTÍNEZ-OTERO, Valentín. Propuestas educativas derivadas de la teoría de la inteligencia unidiversa. Revista Iberoamericana de Educación, Madrid, v. 50, n. 1, p. 1-1 1, 2009.

ROSENTHAL, Robert y JACOBSON, Lenore. Pygmalion en la escuela. Madrid, Marova, 1980.

PALACIOS, Emilio. Benito Jerónimo Feijoo y Montenegro Puga. Benedictino (OSB), teólogo, ensayista. Real Academia de la Historia, Madrid, 2014 (1250 años de la muerte de Benito Jerónimo Feijoo, fundador del ensayo moderno). Disponible en: http://blgrah. rah.es/20 14/04/08/250-anos-de-la-muerte-de-benito-jeronimo-feijoo-fundador-del-ensayo-moderno/ Acceso em: 15 abr. 2014.

PINILLOS, José Luis. Principios de Psicología. Madrid: Alianza, 1999.

RAGEL SÁNCHEZ, Luis Felipe. Evolución histórica de los derechos de la mujer. Anuario de

la Facultad de Derecho, Badajoz, n. 12-13, p. 313-336, 1994-1995.

TYLER, Leona. Diferencias entre los sexos. En: TYLER, Leona. Psicología de las diferencias

humanas. Madrid: Marova, 1984.

Prof. Dr. Valentín Martínez-Otero Pérez Universidad Complutense de Madrid Facultad de Educación Departamento de Teoría e Historia de la Educación Sociopsicobiología de la agresión E-mail | valenmop@edu.ucm.es

Recebido 13 set. 2016 Aceito 9 out. 2016 